Z. klin. Chem. u. klin. Biochem.

8. Jg., S. 394-397, Juli 1970

\title{
Eine Mikromethode zur Bestimmung des „wahren“ Kreatinins
}

\author{
Von H. Müller, R. Kluthe und A. Alexandropoulos \\ Aus der Medizinischen Univ.-Poliklinik Freiburg (Direktor: Prof. Dr. H. Sarre)
}

(Eingegangen am 27. Februar 1970)

Es wird eine Mikromethode zur Bestimmung des „wahren“ Kreatinins beschrieben, die auf der Trennung des Kreatinins von den sogenannten Nichtkreatininchromogenen durch Adsorption an Fullererde mit nachfolgender Messung als Kreatininpikrat beruht. Der Serumbedarf beträgt $100 \mu l$, was gegenüber vergleichbaren Makromethoden eine Verringerung auf $1 / 25$ der üblicherweise benötigten Serummenge bedeutet. Der Zeitaufwand für die Bestimmung ist zudem geringer als für die Makromethode.

\section{A micromethod for the determination of "true" creatinine}

A micromethod is described for the determination of "true" creatinine. This is based on the separation of the creatinine from the so-called non-creatinine chromogens by adsorption onto Fuller's earth, followed by measurement of the creatinine as its picrate. $100 \mu l$ of serum are required, which represents a 25 -fold reduction compared with the amount normally needed for comparable macromethods. The time required for the determination is also less than for the macromethod.

Die Bestimmung des Serumkreatininspiegels gehört zu den Standarduntersuchungen im Rahmen einer nephrologischen Diagnostik, da das Serumkreatinin nach allgemeiner Erfahrung einen zuverlässigen Parameter des Ausscheidungsvermögens der Niere für harnpflichtige Substanzen darstellt $(1,2)$. Bei gleichzeitig erfolgender Bestimmung im Urin läßt sich die Kreatinin-Clearance und damit näherungsweise das Glomerulusfiltrat berechnen.

Wegen ihrer einfachen Handhabung werden in der klinischen Routinediagnostik meist Modifikationen der JAFFÉ-Reaktion (3) benutzt $(4,5)$, die jedoch mit dem Nachteil ungenügender Spezifität behaftet sind. Diese Verfahren liefern höhere Werte als dem wahren Kreatiningehalt des Serums entspricht, da außer Kreatinin noch eine Reihe anderer Substanzen, die sogenannten „Nichtkreatininchromogene“ das Meßergebnis beeinflussen.

Wegen dieser Fehlermöglichkeiten wird an unserer Klinik seit Jahren das ,wahre" Kreatinin nach einer von LøKEN (6) angegebenen Makromethode bestimnt, welche wir für die Bedürfnisse des Routinelaboratoriums geringfügig modifiziert haben. Das Probevolumen beträgt $2,5 \mathrm{~m} l$ Serum.

Dieser relativ große Serumbedarf für eine Einzelbestimmung veranlaßte uns, eine Mikromethode auszuarbeiten. Während die Umstellung der JAFFÉ-Reaktion auf Mikromaßstäbe mit Hilfe eines der handelsüblichen Mikrolitersysteme sehr leicht gelingt, treten bei der Bestimmung des "wahren" Kreatinins als Mikromethode eine Reihe technischer Schwierigkeiten auf. Deshalb halten wir es für angebracht, unsere Arbeitsweise nachstehend $z u$ veröffentlichen.

\section{Prinzip der Methode}

Nach Enteiweißung des Serums wird in saurem Milieu Kreatinin an Fullererde adsorbiert. Die Störsubstanzen verbleiben im Überstand. In alkalischem Milieu kann das adsorbierte Kreatinin wieder aus der Fullererde eluiert und nach Bindung an Pikrinsäure als Kreatininpikrat photometrisch bestimmt werden.

\section{Geräte und Reagenzièn}

\section{Apparatur}

Mikrolitersystem „EPPENDORF“ bestebend aus:

1. Ein Satz Mikropipetten „Marburg“, Pipettenspitzen

2. Mikrospezialzentrifuge

3. Schüttelgerät

4. Mikroabsaugeküvette mit Saugballon

5. Mikroreaktionsgefäße

6. Reaktionsgefäßhalter

Photometer „EPPENDORF“ mit Photozelle $90 \mathrm{~b}$ und Blende $1 \times 2,5 \mathrm{~mm}$.

Speziallöfel zum Abmessen von $8 \mathrm{mg}$ Lloyds-Reagenz.

Herstellung: Ein Streifen dünnen Kupferblechs wird an einem Ende durch Hämmern so bearbeitet, daß eine Eindellung im Sinne eines kleinen Löffels entsteht. Unter Kontrolle mittels einer Mikrowaage muß der Löffel so bearbeitet werden, daß er bei Füllung bis zum Rand $8 \mathrm{mg}$ Fullexerde $\mathrm{fa} ß \mathrm{Bt}$.

Die Genauigkeit der mit dem Löffel zu erzielenden Dosierung wurde folgendermaßen geprüft: Auf 10 vorher ausgewogene Papierfilterscheiben wurde ohne Anwendung übertriebener Sorgfalt je einmal der Inhalt des gefüllten Löffels entleert. Dann wurden die Scheiben nochmals gewogen. Der mittlere, absolute Fehler betrug 0,081 mg entsprechend einer durchschnittlichen Fehlerbreite von $\pm 1 \%$. Die maximale Abweichung vom Sollwert nach oben lag bei $\pm 1,75 \%$, die maximale Abweichung nach unten bei $-1,63 \%$.

Spezialpipette zum Absaugen des Ubberstands.

Herstellung: Eine Pipettenspitze „,rot“ wird erwärmt und ihr unteres Ende in einem Winkel von $30^{\circ}$ so gebogen, daß das Lumen dabei erhalten bleibt. Diese Pipettenspitze kann immer wieder verwendet werden, da sie nur zum Absaugen desjenigen Überstands benutzt wird, der.anschließend verworfen wird.

Reagenzien

1. 10proz. Trichloressigsäure.

2. Lloyds-Reagenz (Fullererde). Bezugsquelle: Serva-Entwicklungslabor, Heidelberg. 


\section{Alkalische Pikrinsäurelösung.}

Neutrale Pikrinsäurelösung wird folgendermaßen hergestellt: Eine gesättigte Pikrinsäurelösung wird filtriert und anschlieBend mit 25proz. $\mathrm{NaOH}$ tropfenweise versetzt, bis ein $\mathrm{pH}$ von genau 7,0 erreicht ist ( $\mathrm{pH}-\mathrm{Meter}$ ).

5 Volumenteile neutraler Pikrinsäure (s. unten) +12 Volumenteile dest. Wasser +1 Volumenteil 5,5 proz. $\mathrm{NaOH}$ werden gemischt.

Die alkalische Pikrinsäurclösung ist bei Aufbewahrung in dunklen Flaschen vor Licht geschützt längere Zeit haltbar.

\section{Ausführung}

$100 \mu l$ Serum $+100 \mu l$ demin. Wasser $+400 \mu / 10$ proz. Trichloressigsäure werden in ein Kunststoffprobengefäß pipettiert. Nach $5 \mathrm{Min}$. ist die Denaturierung der Eiweiße abgeschlossen. Anschließend 2 $1 / 2$ Min. in der Mikrospezialzentrifuge schleudern. Vom Überstand werden genau $400 \mu l$ in ein weiteres Reaktionsgefäß überführt, das vorher schon mittels Speziallöffel mit etwa $8 \mathrm{mg}$ LLoYDs-Reagenz beschickt worden war. Zur Adsorption des Kreatinins 12 Min. im Rotationsmischer schütteln. Der Überstand, der die Nichtkreatininchromogene enthält, muß jetzt quantitativ entfernt werden, was am einfachsten durch Absaugen mittels der gebogenen Spezialpipettenspitze geschieht (Reaktionsgefä $\beta$ in Augenhöhe halten!). Der verbleibende Bodensatz wird mit $400 \mu l$ Pikrinsäure versetzt und zum Eluieren des Kreatinins nochmals $15 \mathrm{Min}$. geschüttelt. $4 \mathrm{Min}$. zentrifugieren. Überstand absaugen und dessen Extinktion im EPPENDORF-Photometer bei einer Wellenlänge von $492 \mathrm{~nm}$ in der Mikro-Absaugküvette gegen einen Leerwert messen. Der Leerwert, der in jeder Serie mitläuft, wird wie die Probe behandelt, wobei statt Serum eine gleiche Menge demin. Wasser eingesetzt wird. Bei Extinktionen über 1,2 muß die Bestimmung mit einem durch demin. Wasser entsprechend verdünnten Serum wiederholt werden.

Urin wird 1:30 verdünnt und dann genauso behandelt wie Serum.

Zur Umrechnung der Extinktionseinheiten in mg Kreatinin $/ 100 \mathrm{~m} l$ Serum muß die Methode mit reinem Kreatinin geeicht und anhand der Eichkurve der Umrechnungsfaktor ermittelt werden.

\section{Anlegen einer Eichleurve}

Bestimmte Mengen von Kreatinin (Fluka, puriss. p. a.) wurden in $0,01 \mathrm{~N} \mathrm{HCl}$ gelöst, derart, daß Kreatininkonzentrationen $z$ wischen $0,75 \mathrm{mg} / 100 \mathrm{ml}$ und $9,4 \mathrm{mg} /$ $100 \mathrm{~m} l$ entstanden. Anhand von Doppelbestimmungen für jeden Wert wurde eine Eichkurve erstellt (Abb. 1). Bis zu einer Kreatininkonzentration von etwa $7 \mathrm{mg} /$ $100 \mathrm{~m} /$ lagen die Meßwerte auf einer Geraden, während oberhalb dieses Punktes das LAmbert-BeErsche Gesetz nicht mehr galt. Die Regressionsgrade wurde sodann für Werte zwischen 0 und $7 \mathrm{mg} / 100 \mathrm{~m} /$ berechnet. Anhand dieser Regressionsgrade ergab sich ein Multiplikationsfaktor von 6,7 zur Umrechnung von Extinktionseinheiten in Kreatininkonzentrationen $(\mathrm{mg} / 100 \mathrm{ml}$ Serum).

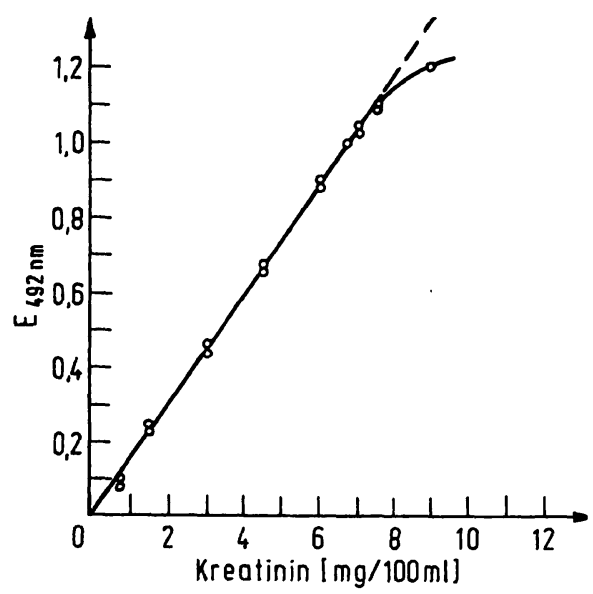

Abb. 1

Eichkurve

\section{Ergebnisse}

\section{Präzision der Metbode}

Eine 10 fach-Bestimmung vom gleichen Serum ergab einen mittleren relativen Fehler von 1,76\%, berechnet als Variationskoeffizient. Für die Bestimmung im Urin wurde bei gleichem Vorgehen ein mittlerer relativer Fehler von $3,78 \%$ gefunden.

\section{Ausbeute der Methode (recovery)}

Ein Serum, dessen Kreatiningehalt durch vorherige Bestimmung bekannt war, wurde mit abgestuften Mengen von Kreatinin versetzt. In mehreren Versuchen wurde im Durchschnitt $97,0 \%$ der zugegebenen Kreatininmenge wiedergefunden mit nur geringen Schwankungen um diesen Wert $(96-98 \%)$.

\section{Vergleich von Mikro- und Makromethode}

Bei 20 Sera mit Kreatininspiegeln zwischen $0,65 \mathrm{mg} /$ $100 \mathrm{~m} l$ und $12,6 \mathrm{mg} / 100 \mathrm{~m} l$ wurde Kreatinin nach der Mikro- und nach der Makromethode (jeweils Doppelbestimmungen) gemessen. Aus Abbildung 2 geht hervor, daß beide Verfahren sehr gut übereinstimmende Werte liefern. Die Punkte streuen nur wenig um die Erwartungsgrade (Korrelationskoeffizient $r=0,999$ ). 20 Urine wurden ebenfalls mit beiden Methoden auf ihren Kreatiningehalt untersucht. Auch hier liefern Mikro- und Makromethode praktisch identische Resultate $(r=0,999)$.

\section{Stabilität des Kreatininpikrats}

Nach Zusatz von Pikrinsäure zu einer Kreatininlösung oder Serum steigt die Extinktion des gebildeten Kreatininpikrats innerhalb der ersten 10-20 Min. steil an, um dann auf einem annähernd horizontalen Niveau zu verharren $(7,8)$. Bei unserem Verfahren vergehen mehr als 20 Min. von der Zugabe der Pikrinsäure bis zum Abschluß der letzten Zentrifugation und der anschlieBenden photometrischen Messung. Wir fanden, daß auch dann die Extinktion nicht völlig stabil ist, sondern einen, wenn auch geringfügigen, weiteren Anstieg zeigt. Aus Gründen der Exaktheit erscheint es daher angebracht, 

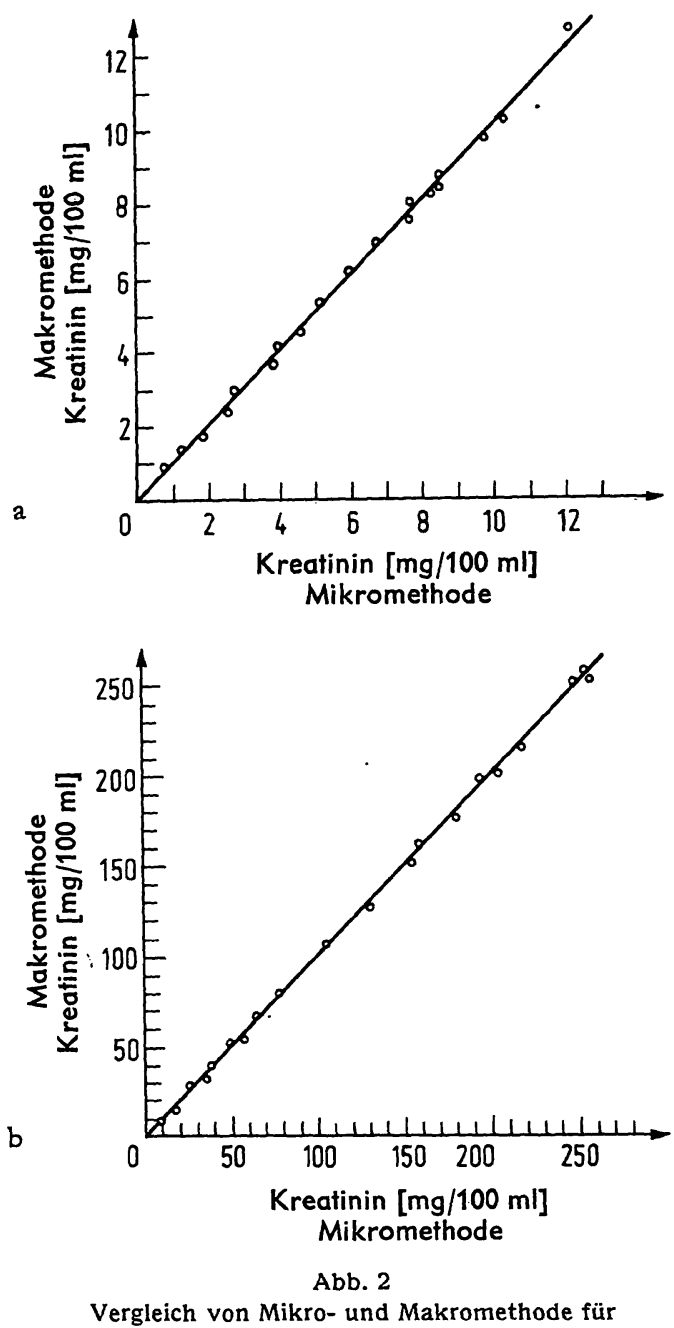

$\begin{array}{ll}\text { a) Serum } & \text { b) Urin }\end{array}$

jeweils innerhalb eines eng begrenzten Zeitraumes z. B. 5-10 Min. nach Ende der letzten Zentrifugation - die Extinktionsmessungen vorzunehmen.

\section{Temperaturabbängigkeit}

Bei Einhaltung der angegebenen Versuchsbedingungen können Temperaturschwankungen in dem Bereich von $21 \pm 3^{\circ} \mathrm{C}$ vernachlässigt werden, so $\mathrm{da} \beta$ man normalerweise ohne Wasserbad auskommt.

\section{Fehlerquellen}

1. Stärkere Schwankungen der Wasserstoffionenkonzentration, wie sie durch fehlerhaft angesetzte Reagenzien verursacht werden können, beeinträchtigen nicht nur die quantitative Elution des Kreatininpikrats aus der Fullererde, sondern können auch den Extinktionskoeffizienten des Kreatininpikrats verändern. Korrekte Versuchsbedingungen sind dann gegeben, wenn die Alkalinität der Probe am Ende der Bestimmung einer 0,03N bis $0,05 \mathrm{~N} \mathrm{NaOH}$ entspricht (6).

2. Innerhalb der Toleranzgrenzen von etwa $15 \%$ um den Sollwert hat die Menge der der Probe zugesetzten Fullererde keinen Einflu $\beta$ auf das Meßergebnis. Bei Benutzung des angegebenen Löffelchens ist der Dosierungsfehler wesentlich kleiner. Um sich die für das Arbeiten mit dem Mikrolöffel unbedingt erforderliche
Routine anzueignen, ist es ratsam, zuerst das Abmessen der Fullererde mit dem Mikrolöffel zu üben und sich dabei mit einer Mikrowaage zu kontrollieren.

3. Unser Schüttelgerät wies den Nachteil auf, daß sich bei längerem Betrieb über einen Zeitraum von $10 \mathrm{Min}$. die an der Achse des Geräts liegenden Proben etwas erwärmten. Um eventuell möglithe Fehler infolge unterschiedlicher Reaktionstemperatur der einzelnen Proben zu vermeiden, empfiehlt es sich, sicherheitshalber die 6 inneren Löcher des Probegefäßhalters freizulassen. In einer Serie können dann immer noch 17 Proben plus ein Leerwert bearbeitet werden.

4. Ein Trennen von Überstand und Sediment durch Dekantieren und Abtropfenlassen der restlichen Flüssigkeit ist im Gegensatz zur Makromethode bei der Mikromethode wegen der kleinen Volumina und der andersartigen Adhäsionskräfte an den Kunststoffgefäßen nicht möglich. Nach Adsorption des Kreatinins an Fullererde muß der die "Nichtkreatininchromogene" enthaltende Uberstand quantitativ entweder mit Filterpapier oder einfacher und genauer mit der gebogenen Pipettenspitze in der beschriebenen Art und Weise abgesaugt werden.

5. Eine leichte Hämolyse des Serums verändert bei unserer Methode das Meßergebnis nicht, während die JAFFÉ-Reaktion in diesem Fall - wegen der gegenüber Serum wesentlich stärkeren Konzentration von „Nichtkreatininchromogenen" im Erythrocyten - höhere Werte ergibt als die Bestimmung in hämolysefreiem Serum (9).

\section{Diskussion}

Die Adsorption des Kreatinins an Fullererde und nachfolgende Bestimmung mittels alkalischer Pikrinsäure darf nach den Untersuchungen von OwEN und Mitarbeitern (7), welche die Methode mit den durch enzymatischen Abbau des Kreatinins erhaltenen Ergebnissen verglichen, als ein weitgehend spezifisches Verfahren angesehen werden.

Dagegen ergibt die direkte Kreatininbestimmung mit alkalischer Pikrinsäure (JAFFí-Reaktion) (3) um 5-20\% zu hohe Werte, da zahlreiche andere Substanzen, die „Nichtkreatininchromogene" ebenfalls mit alkalischer Pikrinsäurelösung eine allerdings wesentlich schwächere Rotfärbung hervorrufen. Dies gilt insbesondere für Acetessigsäure, Aceton, Glycocyamidin, Brenztraubensäure, Bilirubin, Hämoglobin und andere körpereigene Metaboliten sowie manche Pharmaka, wie Ascorbinsäure, Barbitursäure, Nepresol sowie für Testsubstanzen wie Kongorot und Bromthalein. Unvollständige Ausfällung der Eiweißkörper kann zu erheblichen Störungen führen. Lipoide, Lecithin, Cholesterin und andere Lipide können schwer lösliche Pikräte bilden, die Trübungen erzeugen und so auch in geringen Konzentrationen die Extinktionswerte verändern (10). Die Angabe eines allgemein gültigen Korrekturfaktors ist wegen der mannigfaltigen Störungsmöglichkeiten nicht möglich (11). 
Bestimmungsfehler von mehr als $100 \%$ können bei Ketoacidosen, z. B. beim Koma diabeticum auftreten. Die störenden Ketokörper lassen sich durch kurzes Erhitzen entfernen (12), doch kann man danach noch nicht das „wahre" Kreatinin erfassen.

Um die Spezifität der Kreatininbestimmung zu erhöhen, wurden zahlreiche Verfahren angegeben, wie die Abtrennung des Kreatinins durch Ionenaustauscher (13), Sephadex-Gel (14), Papierchromatographie (15), die Beseitigung von Störsubstanzen durch Cersulfat (16) oder die Umwandlung des Kreatinins in Methylguanidin und dessen Bestimmung mittels der SAKAGUCHI-Reaktion (17) u. a. Wegen gewisser methodischer Schwierigkeiten haben sich diese Bestimmungsverfahren, ebenso wie der spezifische, enzymatische Abbau des Kreatinins durch Clostridium ureafaciens (18) in der klinischen Routinediagnostik nicht durchsetzen können.

Sehr gut untersucht hinsichtlich des Einflusses störender Begleitsubstanzen ist ein von BEyermanN (19) entwickeltes Verfahren, wobei Kreatinin als Tetraphenylborat spezifisch ausgefällt wird. Mit der Tetraphenylborat-Methode erhält man die gleichen Werte wie mit dem Adsorptionsverfahren unter Verwendung von Fullererde. BeyermanN zieht daraus den Schluß, daß beide auf verschiedenen Prinzipien beruhende Methoden den Kreatiningehalt richtig wiedergeben (11). Der Zeitbedarf für beide Methoden ist gleich. Bei Routineanalysen macht sich allerdings der hohe Preis des Tetraphenylborats störend bemerkbar. Der Serumbedarf beträgt $2 \mathrm{ml}$. Eine auf diesem Prinzip beruhende Mikromethode ist bisher noch nicht entwickelt worden.

Sowohl die Kreatininbestimmung unter Benutzung von Fullererde im Makromaßstab als auch die Tetraphenylboratmethode erfordern sorgfältiges Arbeiten. Dies gilt in erhöhtem $\mathrm{Maß}$ für unsere Mikromethode.
Die mit der Fullererde-Mikromethode erhaltenen Kreatininwerte sind mit denjenigen der Makromethode identisch. Die Präzision der Fullererde-Mikromethode entspricht bei einem mittleren Fehler von $\pm 1,78 \%$ für Serum derjenigen der Makromethode, für die LøKEN (6) einen Variationskoeffizienten von $\pm 1,1 \%$ angibt. Die Ausbeute (recovery) bei Zusatz unterschiedlicher Mengen von Kreatinin-Reinsubstanz zu einer Serumprobe mit bekanntem Kreatiningehalt lag für die Mikromethode bei durchschnittlich 97,0\%. Für die Makromethode ermittelte LøKEN (6) eine Ausbeute von $98,7 \%$, während genaue Messungen mit radioaktiv markiertem Kreatinin eine Ausbeute von im Mittel $95 \%$ für das Verfahren im Makromaßstab ergaben (11).

Der Zeitaufwand für die Mikromethode ist bei Verwendung des Mikrolitersystems EPPENDORF geringer als derjenige für die Makromethode.

$\mathrm{Da}$ bei einem Anstieg des Kreatinins die „Nichtkreatininchromogene" im Serum nur unwesentlich zunehmen (9), wird der prozentuale Fehler der JAFFÉ-Reaktion bei stärkerem Ausmaß einer Retention harnpflichtiger Substanzen zunehmend kleiner. Zur routinemäßigen Überwachung von Patienten mit stärkeren Nierenfunktionsstörungen mag daher die einfache JAFFÉReaktion ausreichen. Für Untersuchungen im Normalbereich des Kreatinins, insbesondere für anspruchsvollere Zwecke wie die Bestimmung der Kreatininclearance und für wissenschaftliche Untersuchungen ist dagegen den spezifischen Verfahren der Vorzug zu geben. Wie HEALY (20) gezeigt hat, ist die Clearance des „wahren“ Kreatinins besser mit dem durch Inulin bestimmten Glomerulusfiltrat korreliert und zeigt auch weniger aus dem Rahmen fallende, nicht verwertbare Resultate als die Clearance der in die JAFFÉ-Reaktion eingehenden Gesamtchromogene.

\section{Literatur}

1. Sarre, H., Lehrbuch der Nierenkrankheiten, 2. Aufl., ThiemeVlg. (1967). - 2. SchIrmeister, J., H. WILLMANN und H. KIEFER, Dtsch. Med. Wschr. 89, 1018 (1964). - 3. JAFFÉ, M., HoppeSeyler's Z. physiol. Chem. 10, 391 (1886). - 4. Popper, H., E. MANDEL und H. MaYer, Biochem. Z. 291, 354 (1937). 5. Brod, J. und J. H. Sirota, J. Clin. Invest. 27, 645 (1948). 6. Løken, F., Scand. J. Clin. Labotat. Invest. 6, 325 (1954). 7. Owen, J. A., B. Iggo, F. J. Scandrett und C. P. Stewart, Biochem. J. 58, 426 (1954). - 8. SCHIRMEISTER, J., H. WILLMANN und H. KIEFER, Klin. Wschr. 41, 878 (1963). - 9. Doolan, P. D., E. L. Alpen und G. B. Theil, Amer. J. Med. 32, 65 (1962). -
10. Beyermann, K., Z. analyt. Chem. 205, 26 (1964). - 11. BeyermanN, K., W. GeroK und U. Groth, Klin. Wschr. 45, 950 (1967). - 12. KattermanN, R., diese Z. 5, 72 (1967). 13. Polar, E. und J. Metrcoff, Clin. Chem. New York 11, 763 (1965). - 14. McEvoy-Bowe, E., Analytic. Chem. 16, 153 (1966). - 15. PfeIL, D., Z. analyt. Chem. 154, 5 (1957). - 16. Ralston, M., J. Clin. Path., London 8, 160 (1955). - 17. MartiNEz, E. und P. D. Doolan, Clin. Chem. New York 6, 233 (1960): 18. MrLLER, B. F. und R. Dubos, J. biol. Chemistry 121, 457 (1937). 19. Beyermann, K., Amsterdam, Clin. Chim. Acta 17, 47 (1967). 20. Healy, J. K., Amer. J. Med. 44, 348 (1968). 